\title{
Quasi-Elastic Determination of Polymeric Material Moduli Using Vibrational OCT
}

\author{
Frederick H Silver* \\ Department of Pathology and Laboratory Medicine, RWJMS, Rutgers, the State University of New Jersey, USA
}

Submitted: January 01, 2018; Published: January 18, 2018

*Corresponding author: Frederick H Silver, Department of Pathology and Laboratory Medicine, Robert Wood Johnson Medical School, Rutgers, the State University of New Jersey, Piscataway, NJ 08854,USA, Email: silverfr@rutgers.edu/fhsilver@hotmail.com

Abstract

The need to non-invasively and non-destructively measure the mechanical properties of tissues and implants has been a goal of researchers for many years. A variety of methods have been used to evaluate the mechanical properties of tissues over the last 40 years including uniaxial and biaxial tensile testing, indentation and rotational tests, ultrasound elastography (UE), optical cohesion tomography (OCT), optical cohesion elastography (OCE), and vibrational analysis combined with OCT. We have developed a test using vibrational OCT to image and estimate the elastic modulus of tissues and implant materials non-invasively and non-destructively. Using images generated by OCT, maps of the estimated elastic modulus as a function of position can be generated that will be useful in marking the margins of scars and tumors as well as to evaluate surface defects on polymeric materials.

Keywords: Collagen; Extracellular matrix; Polymer; Optical coherence tomography (OCT); Vibrational analysis; Vibrational OCT; Modulus; Mechanical properties

\section{Introduction}

The need to measure the mechanical properties of tissues and implants has been a goal of researchers since the 1970s. The pioneering work of Yamada [1] and Fung [2] illustrated how difficult this goal would be since the behavior of human extracellular matrix (ECM) depends on strain-rate, Poisson's ratio, direction of testing and is time-dependent [3]. A variety of methods have been used to evaluate the mechanical properties of tissues over the last 40 years including uniaxial and biaxial tensile testing, indentation and rotational tests, ultrasound elastography (UE), optical cohesion tomography (OCT), optical cohesion elastography (OCE), and vibrational analysis combined with OCT [4-6]. Many of these techniques require the assumptions that the material is linearly elastic, Poisson's ratio is close to 0.5 and that viscoelasticity does not dramatically affect the resulting properties. However, the behavior of most tissues is that of a non-linear viscoelastic material that has upward curvature to the stress-strain curve. These concerns makes determination of the stiffness (tangent to the stress-strain curve) and other mechanical properties very difficult to quantitatively analyze since the tangent to the stress-strain curve is constantly changing $[3,5,6]$. However, despite all of these problems, there is a need to be able to characterize the mechanical properties of tissues and implants, since this would give researchers valuable information about the properties of tissues and implants used as medical devices. In this paper, we will discuss the use of vibrational optical coherence tomography to determine the quasi-elastic modulus of implants and tissues.

\section{Measurement of the Modulus of Decellularized Dermis and Implant Materials}

The non-linearity of the stress-strain curves of tissues makes determination of the modulus very difficult because the material is non-linear and is viscoelastic. The modulus of a number of extracellular matrices (ECMs) in the past was tested invasively by determination of incremental stress-strain curves. Using incremental stress-strain curves the total stress is divided into elastic and viscous components $[3,7]$. The results indicate that the elastic modulus is independent of strain-rate for strain rates up to $10,000 \%$ per minute [7]; however, to determine the modulus using incremental stress-strain measurements required up to $24 \mathrm{hrs}$ between addition of individual strain increments $[3,7]$. Therefore, this approach is not practical especially in clinical applications. In addition, the test is destructive and invasive since the samples must be cut into strips and tested until failure.

\section{Development of Vibrational Optical Cohesion Tomography (OCT)}

Recently, we have reported the use of vibrational analysis and OCT to characterize the mechanical behavior of decellularized human dermis, pig skin, bovine articular cartilage, subchondral 
bone and silicone rubber $[5,6]$. Our results indicate that the modulus measured using vibrational OCT and that determined from tensile incremental stress-strain curves for decellularized dermis and silicone rubber had correlation coefficients in excess of 0.95 demonstrating that the modulus measured using vibrational OCT was very similar to the tensile modulus measured using incremental stress-strain curves $[5,6]$.

The measured value of the moduli did not depend on an assumed value of Poisson's ratio. Results of studies on decellularized dermis and silicone rubber at frequencies of between 50 and $1000 \mathrm{~Hz}$ suggested that the viscous component of the modulus measured at frequencies at or above the resonant frequency was 3\%-4\% [8] (Figure 1). Based on these results the modulus measured using vibrational OCT was considered to be an approximation of the "elastic modulus" and the viscous component was negligible [8]. While the modulus determined from vibrational OCT is an approximation of the elastic modulus it depends on the strain for tissues since not all the collagen fibers are recruited to bear loads at low strains $[5,6]$.

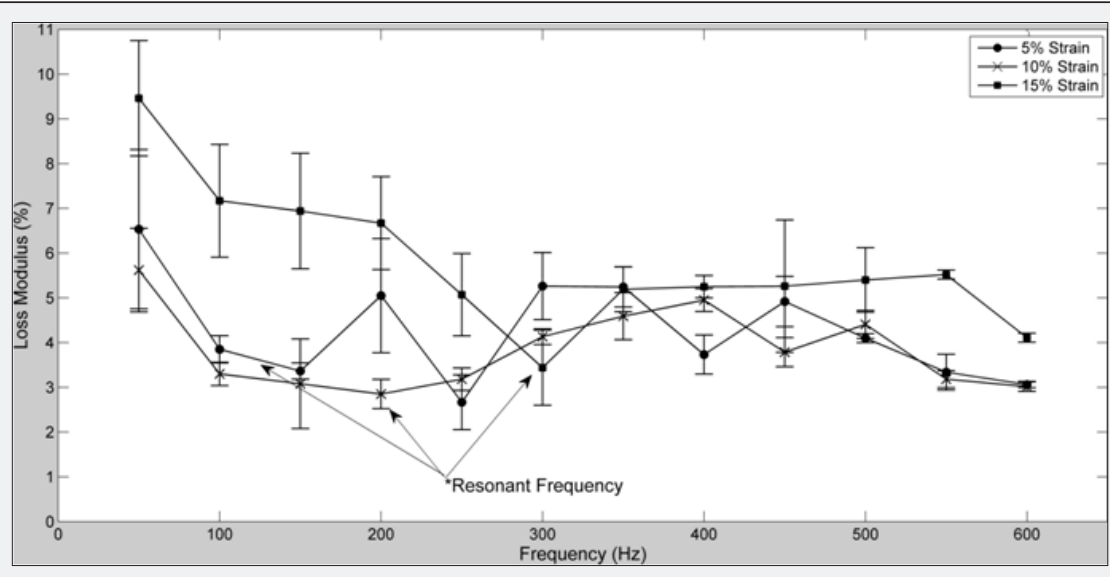

Figure 1: A plot of the loss modulus of decellularized dermis as a function of vibrational frequency and strain; note the loss modulus is lowest at the resonant frequency denoted by the arrows for each strain. The modulus of decellularized dermis is dependent on the strain, since not all the collagen fibers are aligned with the stress direction until the material is stretched to about $15 \%$ strain. This quasi-elastic behavior is similar for silicone rubber (data not shown) except the modulus of silicone rubber is almost independent of strain. The modulus was determined from vibrational OCT as described previously [8].

\section{Use of Vibrational OCT to Measure the Moduli of Skin} in Vivo

Vibrational OCT has been used to image and measure the mechanical properties of skin and scar tissue in vivo. Results of in vivo vibrational OCT studies suggest that the resonant frequency and modulus of normal skin is lower than that of scar tissue (Figure 2) [9] and that of the margins of a healed scar have a resonant frequency different than that of normal skin. Recent results indicate that the margins of a scar can be mapped using vibrational OCT since the resonant frequencies and moduli seen at the interface reflect both the resonant frequency of normal skin and that of the scar tissue [9].
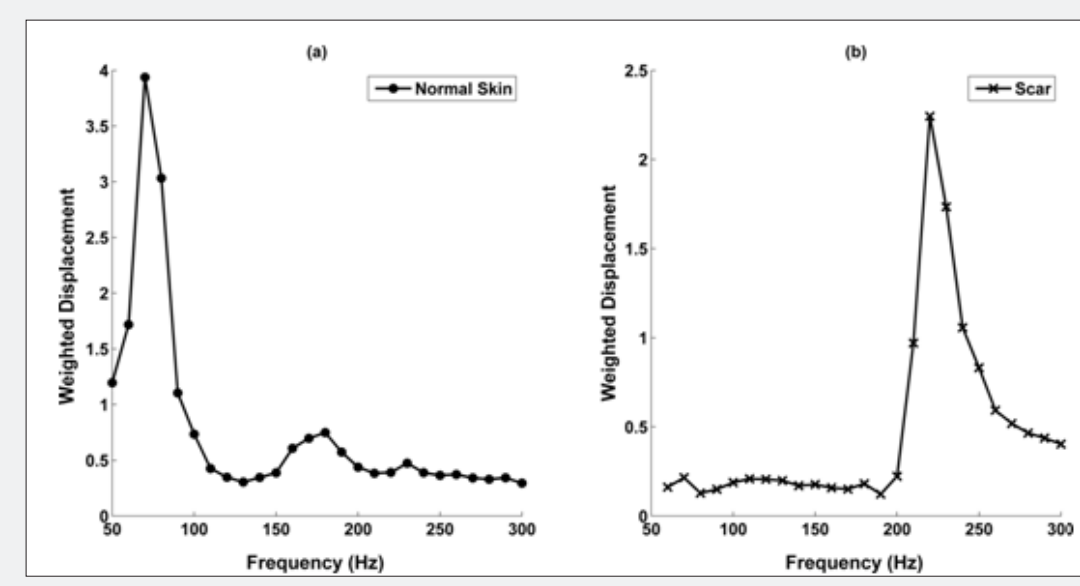

Figure 2 : Vibrational OCT measurements made on human skin and scar tissue. This figure shows the weighted displacement versus frequency for normal skin (a) and scar tissue (b). The major resonant frequencies were $70 \mathrm{~Hz}$ (normal skin) and 220 (scar tissue) [8]. The collagen peak moves to right in normal skin after the skin is stretched beyond the normal skin tension (data not shown). The measurements shown in Figure 2 were made under normal skin tension. The increased resonant frequency of scar tissue is related to the higher degree of collagen fiber orientation in scar tissue as opposed to normal skin. 


\section{Conclusion}

Using vibrational OCT the resonant frequency and moduli of tissues and implants can be measured non-invasively and non-destructively. The numbers generated reflect to a first approximation a quasi-elastic modulus and do not depend on measurement of other parameters. The loss modulus is only 3 to $4 \%$ of the total modulus at frequencies above the resonant frequency. Measurements made using vibrational OCT are calibrated using incremental tensile measurements made on the same sample. Using images generated by OCT, maps of the modulus as a function of position can be generated that will be useful in marking the margins of scars and tumors, stressconcentrations at implant-tissue interfaces, and imperfections on the surface of polymeric materials.

\section{References}

1. Yamada H (1970) Strength of Biological Materials. Williams and Wilkins, Baltimore, MD.

2. Fung YC (1993) Biomechanics: Mechanical Properties of Living Tissue, $2^{\text {nd }}$ edn, Springer, NY, USA.
3. Dunn MG, Silver FH (1983) Viscoelastic behavior of human connective tissues: Relative contribution of viscous and elastic components. Connect Tissue Res 12(1): 59-70.

4. Silver FH, Shah R (2016) Measurement of mechanical properties of natural and engineered implants. Advances in Tissue Engineering and Regenerative Medicine 1: 1-9.

5. Shah R, DeVore D, Pierce MG (2016) Morphomechanics of dermis-A method for non-destructive testing of collagenous tissues. Skin Res Technol 23(3): 399-406.

6. Shah R, Pierce MC, Silver FH (2017) A method for non-destructive mechanical testing of tissues and implants. J Biomed Mater Res A 105(1): 15-22.

7. Silver FH (2006) Mechanosensing and mechanochemical transduction in extracellular matrix. New York: Springer.

8. Shah RG, Silver FH (2017) Viscoelastic behavior of tissues and implant materials: Estimation of the elastic and viscous contribution using optical coherence tomography and vibrational analysis. J Biomed Tech Res 3(1): 105.

9. Shah RG, Silver FH (2017) Vibrational analysis of extracellular matrix scaffolds: comparison of skin, dermis, cartilage and subchondral bone. Adv Tiss Eng Regen Med 2(6): 00048.

\begin{tabular}{l} 
Your next submission with Juniper Publishers \\
will reach you the below assets \\
- Quality Editorial service \\
- Swift Peer Review \\
- Reprints availability \\
- E-prints Service \\
- Manuscript Podcast for convenient understanding \\
- Global attainment for your research \\
- Manuscript accessibility in different formats \\
( Pdf, E-pub, Full Text, Audio) \\
- Unceasing customer service \\
Track the below URL for one-step submission \\
https://juniperpublishers.com/online-submission.php \\
\hline
\end{tabular}

